\title{
Title Treatment of Paroxysmal Dyskinesia
}

\section{Authors:}

Anna Latorre $\mathrm{MD}^{1,2}$, Kailash P. Bhatia FRCP, MD

${ }^{1}$ Department of Clinical and Movement Neurosciences, Queen Square Institute of Neurology University College London, London, United Kingdom

${ }^{2}$ Department of Human Neurosciences, Sapienza University of Rome, Italy

Corresponding author:

Prof Kailash Bhatia

Department of Clinical and Movement Neuroscience

UCL Queen Square Institute of Neurology

University College London

Queen Square, London

WC1N 3BG

Office Tel: 44 (0) 2034488723

k.bhatia@ucl.ac.uk

\section{Synopsis}

Paroxysmal dyskinesia (PxD) are a heterogeneous group of syndromes characterized by the recurrence of attacks of abnormal movements, triggered by detectable factors, without loss of consciousness. The abnormal movements may be dystonic, choreic, ballistic, or a combination of thereof. According to the precipitating factors they are classified in paroxysmal kinesigenic dyskinesia (PKD), paroxysmal non-kinesigenic dyskinesia (PNKD), and paroxysmal exercise-induced dystonia (PED). PxD can have a primary or secondary aetiology. The primary forms are mostly due to a genetic defect, with PRRT, PNKD (MR-1) and SLC2A1 being the most common gene causing PKD, PNKD and PED respectively. However, recent findings have led to a better understanding of the broad spectrum of genetic conditions underlying PxD, highlighting a clinical and genetic overlap among the syndromes and refusing the concept of one gene causing one phenotype.

The treatment of PxD is based on the combination of non-pharmacological and pharmacological approaches. The former consists especially in preventing the attacks, avoiding precipitating factors. This strategy can be sufficient in controlling the symptoms in many cases of PNKD and PED; whereas PKD is characterized by having an exquisite response to antiepileptic drugs. Pharmacological and non-pharmacological treatments effective for PNKD and PED are also available. In PxD refractory to conventional treatment, surgical approach might be an alternative therapeutic option. The course of PRRT2-PKD and MR-1-PNKD is benign, and treatment might not be needed with advancing age. 
Key words (5-8) Paroxysmal dyskinesia, PKD, PNKD, PED, PRRT2, MR-1, SLC2A1, treatment

\section{Key Points}

- Paroxysmal dyskinesia are a heterogeneous group of disorders manifesting as recurrent attacks of abnormal moments (dystonic, choreic, ballistic, or a combination of these), without loss of consciousness

- According to the precipitating factors they can be classified in PKD, PNKD, and PED

- Causes can be primary and secondary. Each phenotype can be associated to different gene mutations, most commonly to PRRT2, PNKD (MR-1) and SLC2A1 gene mutations

- Preventing the attacks avoiding precipitating factors can be sufficient in controlling the symptoms (especially for PED), but pharmacological and other non-pharmacological treatment options are available

- $\quad P K D$ has an exquisite response to AED, particularly CBZ, whereas BDZ can be effective for PNKD. Refractory paroxysmal dyskinesia may respond to surgical treatment

\section{Overview: Nature of the Problem}

\section{Definition}

Paroxysmal dyskinesia $(\mathrm{PxD})$ are a rare heterogeneous group of disorders manifesting as recurrent attacks of abnormal moments, without loss of consciousness (1). The abnormal movements may be dystonic, choreic, ballistic, or a combination of these. In medical literature, the terms "paroxysmal" and "dyskinesia" respectively refer to "sudden attack, recurrence or intensification of a disease" and "involuntary jerky or slow writhing movements, often of a fixed pattern, including tics, myoclonus, chorea and dystonia". It is, therefore, clear that the definition is too broad and could erroneously include conditions that are not generally considered as PXD by movement disorders expert. The following paragraphs will help in clarifying this aspect.

\section{Historical aspects}

PxD was first described in 1892 by Shuzo Kure in a 23-year-old Japanese man, who had frequent movement-induced paroxysmal attacks from the age of 10 (2). Later in 1901, Gowers reported a child with a similar picture, but he considered the attacks as an epileptic phenomenon (3). In 1940, Mount and Reback described a 23-year-old man with intermittent choreo-dystonic attacks of the trunk and extremities and labelled this condition "paroxysmal dystonic choreoathetosis" (4). In this case, the attacks were precipitated by alcohol, coffee or tea intake, fatigue and smoking, and could last several hours. Over the years, more families with a similar disorder were described, showing a clear autosomal dominant pattern of inheritance. In 1967, Kertesz (5) reported other families with 
episodic attacks of involuntary movements; but, differently from the previous description, the attacks were very brief in duration and induced by sudden movements. Moreover, they responded well to anticonvulsants, particularly Carbamazepine (CBZ). Kerstesz called it "paroxysmal kinesigenic choreoathetosis", to differentiate it from "paroxysmal dystonic choreoathetosis". A third type of PxD was introduced in 1977 by Lance (6), who used the term paroxysmal exercise-induced dystonia (PED) to describe a family who had attacks lasting between 5 and $30 \mathrm{~min}$, provoked by prolonged exercise. It was only in 1995 that Demirkiran and Jankovic merged the many terms adopted, organising PxD in three subtypes: paroxysmal kinesigenic (PKD), paroxysmal non-kinesigenic dyskinesia (PNKD), and PED (7). A fourth subtype of PxD, characterised by attacks occurring during sleep without detectible trigger, was also proposed (i.e., paroxysmal hypnogenic dyskinesias); however, it has been later discovered to be a form of autosomal dominant nocturnal frontal lobe epilepsy in most of the cases and therefore no longer regarded as a form of PxD.

\section{Classification}

The clinical classification of PxD is mostly based on the criteria proposed by Demirkiran and Jankovic (1995)(7), subsequently refined by Bruno et al. (2007)(8). This classification relies on the precipitating event, which is considered the best predictor of clinical course as well as the most reliable predictor of the underlying genetic cause $(7,9)$. According to precipitating factors, PxD can be classified as PKD, PNKD and PED. Secondary categorization is based on duration of the attacks. Finally, a tertiary categorization involves presumed aetiology: primary (familial/sporadic) or secondary (Table 1). More recently, Erro et al. 2014 (9) proposed a new classification scheme of primary PxD, that includes all the above mentioned categorizations but takes also into account the more recent genetic discoveries. This new classification consists of two axes: clinical features (axis 1 ) and genetic determinants (axis 2), as shown in Table 2. 
Table 1. Clinical features of paroxysmal dyskinesia

\begin{tabular}{|l|l|l|l|}
\hline & PKD & PNKD & PED \\
\hline Age at onset & Childhood/teens & Infancy/childhood & Variable \\
\hline Clinical semiology & Chorea/dystonia & Chorea/dystonia & Dystonia \\
\hline Precipitating factors & Sudden movement & $\begin{array}{l}\text { Coffee, tea, alcohol, } \\
\text { stress, fatigue }\end{array}$ & Prolonged exertion \\
\hline Duration of attacks & Seconds to minutes & Minutes to hours & $\begin{array}{l}\text { Subside with rest } \\
\text { (usually 15-40 } \\
\text { minutes) }\end{array}$ \\
\hline Frequency of attacks & $\begin{array}{l}\text { From 1/month up to } \\
100 / \text { day }\end{array}$ & $\begin{array}{l}\text { From 1/year up to 2- } \\
\text { 3/day }\end{array}$ & \begin{tabular}{l} 
Dependent on exercise \\
\hline
\end{tabular} \\
\hline
\end{tabular}

PKD: paroxysmal kinesigenic dyskinesia, PNKD: paroxysmal non-kinesigenic dyskinesia, PED: paroxysmal exercise-induced dystonia

Table 2. Classification of primary paroxysmal dyskinesias according to clinical (Axis I) and genetic (Axis II) characteristics

Axis I: Clinical characteristics

A) Inclusion criteria (1 plus one of $2 a$, b or c)

1. Paroxysmal attacks of dystonia, chorea, ballism (or a mixture of those) with sudden onset and variable duration (seconds to hours).

2. Paroxysmal dyskinesia are categorized according to the "trigger factor" into one of the following:

a. Paroxysmal kinesigenic dyskinesia: attacks are triggered by sudden movements, acceleration, or intention to move

b. Paroxysmal non-kinesigenic dyskinesia: attacks are triggered by coffee, alcohol, and other non-kinesigenic precipitants

c. Paroxysmal exercise-induced dyskinesia: attacks are triggered by prolonged exercise

B) Exclusion criteria (both 1 and 2)

1. Symptoms are due to another neurological condition

2. Symptoms are psychogenic

Axis II: Genetic characteristics

1. Mutations confirmed in one of the known genes (i.e., PRRT2, MR-1, KCNMA1, SLC2A1)

2. No mutations in one of the known genes or genetic testing has not been performed (undetermined forms) 
PKD is the most common PXD and it is characterized by brief, self-limiting attacks, precipitated by sudden movements, such as standing up quickly from a chair. A sudden increase in speed, amplitude, or strength or even the sudden additions of new actions during ongoing steady movements may induce an attack too $(7,10)$; while startle, sound/photo/vestibular stimulation, hyperventilation, or stress can also favour them (10). Usually the attacks last few seconds up to 1 minute but are multiple during the day (11). The frequency ranges from less than $1 /$ month to up to 100/day. The clinical manifestation exhibited may be dystonia, chorea, ballismus, or a combination thereof; but among these, dystonia is the most common. The attacks may be focal, multifocal or generalized; they most often involve one or two limbs, but trunk and/or speech (through orofacial involvement) can also be affected $(9,10)$. Most patients experience "aura" abnormal sensation prior the involuntary movements, such as numbness or "pins and needles" in the affected limb or the epigastric region (11). The "aura" can be used as warning sign to prevent the attacks, for instance by slowing down or "holding tight" the affected limb (9). There is no pain or loss of consciousness during attacks, and no postictal confusion or drowsiness $(11,12)$. Onset age in PKD is usually between 7 and 15 years but has been described up to 40 years. There is a higher prevalence in males (4:1, even up to $8: 1)$ in the sporadic form but not in familial cases (13).

Mutations in the PRRT2 gene are the cause of isolated PKD in about $40 \%$ to $90 \%$ of the cases (14-18), depending on case ascertainment $(9,19)$. In PKD, PRRT2 is inherited in an autosomal dominant manner but with variable penetrance ranging from $80-90 \%$ in familial cases to $30-35 \%$ in sporadic cases (20). In PRRT2 carriers, attack frequency peaks during puberty and decreases with age. PRRT2 mutations can cause also two related disorders, namely infantile convulsions and choreoathetosis (ICCA) and benign familial infantile epilepsy (BFIE), and it has been proposed that ICCA, BFIE, and PKD may represent a spectrum of related disorders (21). In addition, it is known that PRRT2 mutations can induce additional phenotypes including episodic ataxia and familial hemiplegic migraine $(19,22)$. When present in a single subject or in the family, these features make the occurrence of PRRT2 mutations more likely. Not all cases of PKD are due to mutations in the PRRT2 gene, and while some cases remain of unknown aetiology, others have been attributed to different genes. For instance, mutations in SCN8A can be a cause of the ICCA syndrome (23), as well as episodic dystonia (24). Possible PKD cases have also been attributed to mutations in SLC2A1, PNKD (MR-1), KCNMA1, and KCNA1 gene $(25,26)$. More complex phenotypes including developmental delays, intellectual disability and language abnormalities, minor dysmorphic facial features, and/ or autism spectrum disorder associated with PKD should raise the suspicion of $16 \mathrm{p} 11.2$ (micro)deletions (27). 
PNKD

The typical PNKD phenotype is characterized by dystonic and/or choreic attacks, lasting from minutes to hours. Precipitating factors include coffee, tea, alcohol and stress, whereas attacks may be alleviated by sleep. Less frequent triggers comprise change in external temperature, fever, menstruation, and tiredness. The frequency of the attacks is rarely more than 1 a day and most commonly 1attack/week (9). The dyskinesias can be generalized or unilateral/focal. They often start in one limb and then spread over the body and become generalized. Speech impairment due to face involvement, with oral dyskinesia or tongue dystonia, can be seen, and occasionally other additional features including oculogyric crises, blepharospasm, risus sardonicus, inability to move, and pain have been reported (9). Prodromal symptoms, when present, include weakness, shortness of breath, and migraine. Onset is usually in infancy or early childhood (9). Reliable data on PNKD gender prevalence are not available.

Mutations of the myofibrillogenesis regulator 1 (MR-1) gene were found to be causative of PNKD (28), and the MR-1 gene was consequently renamed as the PNKD gene. In patients carrying the gene, a general tendency to decreasing attack frequency with aging has been described.

While PNKD due to MR-1 mutations manifests as isolated PxD, in several gene mutations that have been recently linked to the PNKD spectrum, the involuntary movements are combined with other neurological features. For instance, in PNKD due to KCNMA1 gene mutations PxD are combined with a personal or familial history of epilepsy or neurodevelopmental delay (29). PNKD can also be associated with mutations in SLC2A1 (30, 31), ATP1A3 (32-34), ADCY5 (35), or in genes encoding the branched-chain a-ketoacid dehydrogenase complex (maple syrup urine disease) $(36,37)$. Of note, ADCY5 mutations can cause variable phenotypes and may manifest, even within the same patient, with PKD and PNKD $(35,38)$; while ATP1A3, in the context of alternating hemiplegia of childhood, can manifest with hemidystonic attacks resembling PNKD.

PED

The third group of PxD was recognized by Lance (1977)(6), as, differently from PKD, the attacks were not brought on by sudden movements but by physical exhaustion after continuous exertion. Indeed, by definition, PED are precipitated by prolonged or sustained exercise. In some cases, fasting, stress and anxiety could trigger the episodes as well (9). Most commonly the attacks last from 15 to 40 minutes, and rarely less than 5 minutes (9). Frequency of attacks ranges from several per day to $1 /$ month, with the majority of the patients reporting several attacks per week. The most common 
presentation is dystonia, but isolated chorea has been also described. It usually has focal/unilateral involvement affecting the lower limbs, and generalization of attacks is rather unusual (22). Additional features reported during the attacks include oculogyric crises, gait disturbances, clumsiness, weakness, and migraine (9).

Mutations in SLC2A1 gene are the main cause of PED, which can be isolated or part of a more complex phenotype $(31,39-44)$. SLC2A1 encodes the glucose transporter type 1 (GLUT1), a membrane-bound protein that facilitates glucose transfer across the blood-brain barrier. Heterozygous mutations in SLC2A1 result in the GLUT1 deficiency syndrome, which is a complex disorder characterized by intellectual impairment, epilepsy, microcephaly, movement disorders including paroxysmal forms. PED is considered as a non-classical variant of the GLUT 1 deficiency syndrome (43), inherited in an autosomal dominant manner, although most cases are de novo (45). Pyruvate dehydrogenase complex-E2 (PDC-E2) deficiency and mitochondrial short-chain enoyl-CoA hydratase deficiency (ECHS1) are two potentially treatable neurological disorders rarely reported to have an initial presentation with only isolated $\operatorname{PED}(46,47)$. Other possible causes of PED are youngonset Parkinson's disease due to Parkin mutation $(48)$ and GCH1 mutations $(9,49)$.

\section{Summary}

PxD are characterized by recurrent attacks of abnormal movements, typically dystonia, chorea or a combination of them, without loss of consciousness. According to the precipitating factor, PxD can be classified in three main subtypes: PKD, PNKD and PED. Each subtype is associated with a causative gene, respectively PRRT2, PNKD (MR-1) and SLC2A1; however, recent genetic findings have extended the spectrum of genes associated to these syndromes, suggesting certain degree of clinical and genetic overlap and refusing the concept that one phenotype is attributable to one single aetiology (Table 3). Of note, PxD can also be secondary to a variety of acquired, immunological and neurodegenerative causes (50) (Table 4). In this case, the clinical picture might different from the classical presentation, as they occur later in life compared with the main genetic forms, and manifest with additional signs or symptoms that guide the diagnostic workup. 
Table 3. Most common genetic causes of paroxysmal dyskinesia

\begin{tabular}{|c|c|c|c|c|}
\hline Gene & Subtype & Inheritance & $\begin{array}{c}\text { Other } \\
\text { paroxysmal } \\
\text { disorders }\end{array}$ & Other features \\
\hline PRRT2 & PKD & $A D$ & $\begin{array}{c}\text { Epilepsy, } \\
\text { migraine, } \\
\text { FHM, ataxia }\end{array}$ & - \\
\hline MR-1 & PNKD (PKD) & $A D$ & Migraine (rare) & - \\
\hline SLC2A1 & PED (PKD, PNKD) & $A D$ & Ataxia, epilepsy & $\begin{array}{l}\text { Anaemia, } \\
\text { hypotonia, } \\
\text { spasticity }\end{array}$ \\
\hline KNCMA1 & PNKD & $A D$ & Epilepsy & $\begin{array}{c}\text { Mental } \\
\text { retardation }\end{array}$ \\
\hline SCN8A & PKD & $A D$ & Epilepsy & $\begin{array}{c}\text { Mental } \\
\text { retardation }\end{array}$ \\
\hline ECHS1 & PED & AR & - & Leigh Syndrome \\
\hline PDC-E2 & PED & $A R$ & - & Leigh Syndrome \\
\hline ADCY5 & $\begin{array}{c}\text { PNKD (PKD, } \\
\text { nocturnal) }\end{array}$ & $A D$ & & $\begin{array}{c}\text { Axial } \\
\text { hypotonia, } \\
\text { non-paroxysmal } \\
\text { dystonia and } \\
\text { chorea }\end{array}$ \\
\hline ATP1A3 & $\begin{array}{c}\text { PNKD } \\
\text { (hemidystonic) }\end{array}$ & & $\begin{array}{l}\text { Hemiplegia, } \\
\text { ataxia }\end{array}$ & - \\
\hline $\mathrm{GCH} 1$ & PED & $A D$ & - & Parkinsonism \\
\hline Parkin & PED & AR & - & Parkinsonism \\
\hline
\end{tabular}

$A D$ : autosomal dominant, $A R$ : autosomal recessive, FHM, familial hemiplegic migraine, PDC: pyruvate dehydrogenase complex, PED: paroxysmal exercise-induced dyskinesia, PKD: paroxysmal kinesigenic dyskinesia, PNKD: paroxysmal non-kinesigenic dyskinesias

In parenthesis, less common subtype. 
Table 4. Secondary causes of paroxysmal dyskinesia

\begin{tabular}{|c|c|c|c|c|}
\hline $\begin{array}{l}\text { Immune } \\
\text { mediated } \\
\text { disorders }\end{array}$ & Vascular & $\begin{array}{l}\text { Metabolic } \\
\text { causes }\end{array}$ & Trauma & Other \\
\hline $\begin{array}{c}\text { Multiple } \\
\text { sclerosis and } \\
\text { other } \\
\text { demyelinating } \\
\text { diseases }\end{array}$ & Stroke & Hypo/hyperglycaemia & $\begin{array}{l}\text { Central } \\
\text { and } \\
\text { peripheral }\end{array}$ & Basal ganglia calcifications \\
\hline $\begin{array}{c}\text { Autoimmune } \\
\text { encephalopathy } \\
\text { (anti-VGKC, } \\
\text { Anti-Caspr2, } \\
\text { Hashimoto) }\end{array}$ & Moyamoya & $\begin{array}{l}\text { Hypocalcaemia/hypoparathyroidism/ } \\
\text { pseudohypoparathyroidism }\end{array}$ & & $\begin{array}{l}\text { Central pontine } \\
\text { myelinolysis }\end{array}$ \\
\hline $\begin{array}{c}\text { Systemic } \\
\text { autoimmune } \\
\text { disorders } \\
\text { (SLE- } \\
\text { APS-Behcet's } \\
\text { disease) }\end{array}$ & $\begin{array}{l}\text { Cerebral } \\
\text { palsy }\end{array}$ & Thyrotoxicosis/hypothyroidism & & Kernicterus \\
\hline $\begin{array}{l}\text { Parry-Romberg } \\
\text { syndrome }\end{array}$ & & Wilson's disease & & Encephalitis/postinfectious \\
\hline $\begin{array}{c}\text { Paraneoplastic } \\
\text { limbic } \\
\text { encephalitis }\end{array}$ & & Maple syrup urine disease & & Brain neoplasm \\
\hline Celiac disease & & Lesch-Nyhan disease & & $\begin{array}{c}\text { Early-onset Parkinson's } \\
\text { disease }\end{array}$ \\
\hline & & & & Functional disorders \\
\hline
\end{tabular}

APS: antiphospholipid syndrome, SLE: systemic lupus erythematosus, VGKC: voltage gated potassium channel-complex 


\section{Patient Evaluation Overview}

It is generally assumed that clinical examination of PxD is normal between the attacks; however, while this might be the case for PRRT2-PKD and for MR-1-PNKD, it is not necessarily true for the other forms as in many cases they present with additional features. Therefore, the criterion of normal interictal examination should be avoided.

The first relevant step of the diagnostic process is to obtain a detailed personal clinical history. Important features that should be considered comprise attack's phenomenology, triggers, and duration as well as family history and comorbidities. If possible, the neurological examination should be performed both during and between the attacks, to identify interictal examination findings that may allow for diagnostic possibilities to be narrowed. When attacks do not occur in the clinical settings, videotapes should be encouraged.

While the disorder is intermittent in nature, it does not wax-and-wane over a period of time such as tics. Moreover, considering the phenomenology, it ranges from dystonia to chorea, and rarely involves ballism, but does not encompass tremor or myoclonus. In case of unusual features, such as the lack of specific and consistent triggers, variable durations and adulthood onset, secondary causes need to be excluded, including functional disorders.

Paroxysmal attacks comprise also epilepsy, tonic spasms, tetany, neuromyotonia, periodic paralyses and episodic ataxias, which need to be excluded clinically or by additional investigations whenever appropriate.

PED diagnosis can be supported by a low cerebrospinal fluid/serum glucose ratio $(<0.60)$, but as for the other syndrome it is confirmed by genetic analysis. Some cases could remain unsolved, but treatment is to be pursued empirically.

\section{Summary}

The evaluation of patients with PxD is based on ictal and interictal clinical examination, as well as a thorough medical history. The latter should be focused on attacks features (such as precipitating triggers, duration, and phenomenology), possible additional symptoms and detailed family history. The clinical diagnosis can be confirmed by means of appropriate genetic test, however a definitive cause is not always found. In that event, treatment should be started on empirical base. When medical history points towards secondary causes, additional investigations might be pursue as appropriate. 


\section{Management Goals}

The management of PxD is focused on the reduction of attacks frequency and the prevention of secondary complications such as falls or interference with activities (for instance driving). This goal can be achieved by avoiding precipitating triggers, and/or preventing the attacks by pharmacological and non-pharmacological treatments.

If comorbidities, like epilepsy, are present, appropriate treatment should be considered. Importantly, possible side effects of the drugs used, should be monitored.

There are no guidelines for the treatment of PxD, which is based on clinical experience and known pathological mechanisms.

In secondary forms of PxD, treatment is mainly focused on the underlying cause, especially when it is reversible.

\section{Pharmacologic Treatment Options}

PKD

PKD is characterized by their exquisitely response to antiepileptic drugs (AEDs). The first-line of treatment is $C B Z$, at low dose, but phenytoin is often used too $(9,51)$ (Table 5). A dramatic response to them is seen especially in PRRT2-PKD compared to other forms $(52,53)$, although treatment failure to AEDs has been reported in homozygous or compound heterozygous PRRT2 mutation carriers $(54,55)$.

CBZ and oxcarbazepine appear to be equally effective (56), but other AEDs, such as phenobarbital (57), levetiracetam (58), gabapentin (59), valproic acid (9), lamotrigine (60), and topiramate (61), have been proven to be beneficial to same extent too.

The use of these drugs is based on class IV level of evidence, e.g. observational studies without controls.

The biological mechanisms underlying PKD are not entirely clear, therefore the reason why CBZ is the most effective drug is still not known. It has been proposed that the mutant PRRT2 interacts with the SNAP-25, a presynaptic Q-SNARE protein involved in the fusion of neurotransmitter vesicles to the cellular membrane, which modulates the kinetics of voltage- gated $\mathrm{Ca} 2+$ channels leading to neuronal hyperexcitability (62). On this basis, it has been suggested that any voltage-gated sodium channel blockers (such as CBZ, phenytoin, lacosamide etc.) could be potentially therapeutic. 
The effect of conventional AEDs is limited in PNKD, but symptoms may respond to benzodiazepines (BDZ), which represents the first-line treatment option. Among them, the most commonly used are clonazepam and diazepam (class IV level of evidence) (Table 5), as either prophylactic or rescue drugs. It has been shown that they are able to reduce both frequency and severity of the attacks in up to $97 \%$ of the patients (8). Other BDZ, including lorazepam, can be effective too. Oxcarbazepine has been recently reported to be beneficial in one case (63), whereas CBZ is ineffective in the majority of patients (64). The effect of other drugs on PNKD have been tried with partial success (haloperidol, anticholinergics, gabapentin, levetiracetam, nitric oxide synthetase inhibitors, adenosine agonists/antagonists, acetazolamide, piracetam and levodopa (65-67)).

ADCY5 patients may have mild functional gain with clonazepam or clobazam, but whether these drugs improve also the paroxysmal episodes it is not specifically reported (68). In ATP1A3, the hemidystonic attacks can be treated by flunarizine, a calcium channel blocker, with dose ranging from 5 to $20 \mathrm{mg} /$ day; however, there are reports of response of hemiplegias/dystonias episodes also to topiramate, ketogenic diet, aripiprazole, steroids, amantadine, oral ATP (69). 
Table 5. Most common pharmacological treatment for paroxysmal dyskinesia

\begin{tabular}{|c|c|c|c|}
\hline Drug & Daily dosage & Side-effects & Effective for \\
\hline CBZ & $50-200 \mathrm{mg}$ & $\begin{array}{l}\text { Skin rash (particularly } \\
\text { in people of Asian } \\
\text { descent), aplastic } \\
\text { anaemia, } \\
\text { agranulocytosis, } \\
\text { dizziness, drowsiness, } \\
\text { nausea, vomiting, dry } \\
\text { mouth, oedema, loss } \\
\text { of balance } \\
\text { or coordination }\end{array}$ & PKD \\
\hline Oxcarbazepine & $75-300 \mathrm{mg}$ & As CBZ & PKD \\
\hline Phenytoin & $100-200 \mathrm{mg}$ & $\begin{array}{l}\text { Headache, nausea and } \\
\text { vomiting, } \\
\text { constipation, } \\
\text { dizziness, drowsiness, } \\
\text { slurred speech, loss of } \\
\text { balance or } \\
\text { coordination, } \\
\text { insomnia, cardiac } \\
\text { arrhythmias, skin } \\
\text { reactions }\end{array}$ & PKD \\
\hline Lacosamide & $50-100 \mathrm{mg}$ & $\begin{array}{l}\text { Dizziness, spinning } \\
\text { sensation, loss of } \\
\text { balance or } \\
\text { coordination, blurred } \\
\text { vision, nausea and } \\
\text { vomiting, drowsiness, } \\
\text { tiredness, headache, } \\
\text { skin reactions }\end{array}$ & PKD \\
\hline Clonazepam & Low dose & $\begin{array}{l}\text { Alertness decreased; } \\
\text { drowsiness; } \\
\text { dysarthria; fatigue; } \\
\text { headache; } \\
\text { hypotension; mood } \\
\text { altered; muscle } \\
\text { weakness; nausea; } \\
\text { withdrawal syndrome } \\
\text { (at low dose) }\end{array}$ & PNKD \\
\hline Diazepam & Low dose & As clonazepam & PNKD \\
\hline
\end{tabular}

CBZ: carbamazepine, PKD: paroxysmal kinesigenic dyskinesia, PNKD: paroxysmal non-kinesigenic dyskinesia 
Compared to other forms of PxD, PED due to GLUT1 mutations respond less to pharmacological treatment (64), while lifestyle and diet modifications are very important in preventing the attacks. Nevertheless, partial benefit has been reported with levodopa, trihexyphenidyl and BDZ $(7,13)$. If associated to Parkinson's disease or GCH1 mutations, PED improves with levodopa; whereas in ECHS1, the paroxysmal attacks can respectively respond to a mitochondrial cocktail including thiamine, riboflavin, carnitine, coenzyme $Q$, vitamin B6 and vitamin C (70).

\section{Non-pharmacologic Treatment Options}

PKD

Lifestyle: avoidance of established trigger, i.e. sudden movements. Stress, sleep deprivation, anxiety, and other triggers can increase the likelihood for PKD episodes, therefore their control can help in preventing attacks.

$P N K D$

Lifestyle and diet: avoidance of methylglyoxal-containing food and beverages such as alcohol, coffee, tea and chocolate may benefit these patients, as well as the avoidance of other predisposing factors, such as fatigue. Lifestyle modifications and diet can reduce or almost abolish attacks in up to onethird of patients with MR- 1 mutations (71).

PED

Lifestyle and diet: prolonged continuous exertion in PED may prevent the occurrence of attacks. In case of GLUT1 deficiency, PED can respond to ketogenic diet (72), but compliance to it can be rather poor and the modified Atkins diet, with less strict fat-to-non-fat ratio and no restriction of food or fluid intake, has been proposed as an alternative, with good results (73). More recently, triheptanoin, an odd-chain triglyceride which acts by replenishing metabolic intermediates in the Krebs cycle, has been shown to dramatically reduce the attacks in PED, with the advantage to be better tolerated than Atkins diet (74).

Ketogenic diet is successful also for the treatment of PDC-E2 deficiency (75). 


\section{Combination Therapies}

There are not reports on the use of combination therapies for the treatment of primary PxD, unless the goal is to address both the paroxysmal attacks and comorbidities (such as epilepsy, nonparoxysmal dystonia etc.).

Acetazolamide it might be a useful adjunct to CBZ in the treatment of PKD, especially when due to demyelinating lesions (13).

\section{Surgical Treatment Options (if applicable)}

PKD

A surgical approach for the treatment of PKD was tried in four members of the same family, positive for PRRT2 mutations, with benefit. In two members, unilateral stereotactic surgery was performed in 1967 , which resulted in complete resolution of the episodes. Based on this result, other two components of the family similarly affected, despite the good response to CBZ which however reduced but not completely stopped the attacks, decided to undergo the same surgery, consisting of right ventro-oral thalamotomy. Following surgery, the number of attacks reduced significantly in one patient and completely disappeared in the other one (76).

PNKD

There are two reports on the effective treatment of PNKD with deep brain stimulation (DBS). The first (77) is about a 26-year-old man, with a very long history of mental retardation, chorea and episodes of flexion and jerky movements of the legs, arm, neck and face. These episodes were classified as PNKD, although his condition remained undiagnosed. He underwent implantation of bilateral DBS in the globus pallidus internus (GPi), with a significant and sustained improvement of the attacks, as well as balance, gross motor function and walking. In the second report, two patients clinically diagnosed with PNKD, refractory to conventional treatment, had a good response to GPi DBS with completely suppression of the PxD (78).

Bilateral GPi DBS can improve the episodic choreoathetoid and dystonic movements in ADCY5 (68, 79).

PED

In a case of PED, of unknown aetiology, the dystonic attacks of the right foot ceased completely after left posteroventral medial pallidotomy (80). 


\section{Treatment Resistance/Complications/Disease Recurrence}

In most of the patients affected by PKD and PNKD, the symptoms can be easily controlled by the combination of non-pharmacological and pharmacological therapies, with low chance of disease recurrence. The response to the pharmacological treatment seems to be related to the underlying cause, with PRRT2-PKD and MR-1-PNKD being the most successful responders to conventional treatment. In small numbers of refractory cases, surgical approaches have been successful. Treatment of PED largely relies on the avoidance of attack triggers, and a good compliance and response to non-pharmacological treatment has been reported.

The possible side-effects are related to the drug used, as detailed in the tables. Worth mentioning, the risk of hypersensitivity reactions to CBZ is increased by the presence of specific human leukocyte antigen (HLA) alleles. The HLA-B*15:02 allele is strongly associated with CBZ-induced StevensJohnson syndrome/toxic epidermal necrolysis in populations where this allele is most common, such as Asian populations. In these populations, the use of CBZ should be avoided and an alternative selected.

\section{Evaluation of Outcome, Adjustment of Treatment, and Long-Term Recommendations}

Treatment outcome is based on the recurrence of the attacks, and therefore mostly on patients' report. In this regard, it might be useful to ask patients to keep a diary of the episodes, specifying the duration and precipitating factors. In case of poor response to the first-line treatment, after adjusting the dose of the recommended drug (keeping in mind that PKD and PNKD usually respond to low dose of AEDs/BDZ), the other options should be pursued and chosen according to their sideeffect profile and patient comorbidities. Differently from PED due to GLUT1 deficiency, the frequency of the episodes in PKD and PNKD decreases with advancing age, and treatment might be unnecessary by that time.

\section{Conclusion / Summary}

PxD defines clinical heterogeneous syndromes distinguished by the recurrence of attacks of abnormal movements, triggered by detectable factors, without loss of consciousness. According to the precipitating factors, PXD are classified in PKD, PNKD, and PED; however, other features, such as duration of the attacks, response to treatment, and aetiology might differentiate them. PxD can be further stratified into primary and secondary disorders. The primary are mostly due to a genetic 
defect, with PRRT, PNKD (MR-1) and SLC2A1 being the most common gene involved and causing respectively PKD, PNKD and PED. Nevertheless, the spectrum of genes associated to these syndromes have been broaden by recent findings, highlighting a clinical and genetic overlap among these syndromes and declining the one-gene-one-phenotype notion.

The clinical diagnosis of PxD is based on ictal and interictal neurological examination, a detailed personal and family medical history, and presence of comorbidities. The clinical diagnosis can be confirmed by means of appropriate genetic test or next generation sequencing approaches. If the clinical evaluation suggest secondary causes, additional investigations should be pursued as appropriate.

The treatment of PxD is based on the combination of non-pharmacological and pharmacological approaches. PKD has an excellent response to AEDs (especially CBZ), whereas in many PNKD and PED cases the symptoms can be controlled by avoiding the precipitating factors. In case this is not sufficient, the use of drugs, such as BDZ for PNKD, and diet changes, such as ketogenic or Atkins diet for PED due to GLUT1 deficiency, can be effective. Moreover, PKD and PNKD have a benign course, and the recurrence of involuntary movements' episodes tends to decrease over the years. Patients with a known genetic cause, such as PRRT2 or PNKD (MR-1), have a better response to conventional treatment compared to the undiagnosed ones; however, in the latter it is recommended to start the appropriate treatment on empirical base. Of note, in PxD refractory to conventional treatments, surgical approach should be keep in mind as an alternative option. 


\section{Disclosures}

K.P.B. holds research grants from NIHR RfPB, MRC Wellcome Strategic grant (Ref. no.: WT089698) and PD UK (Ref. no.: G-1009) and has received honoraria/financial support to speak/attend meetings from GSK, Boehringer-Ingelheim, Ipsen, Merz, Sun Pharma, Allergan, Teva Lundbeck and Orion pharmaceutical companies. KB receives royalties from Oxford University press and a stipend for MDCP editorship.

A.L. has nothing to disclose.

\section{REFERENCES}

1. Bhatia KP. The paroxysmal dyskinesias. J Neurol. 1999;246(3):149-55. PubMed PMID: 10323309.

2. $\quad \quad$ Kure S. Atypical Thomsen's disease. J Tokyo Med Assoc. 1982(6):505-14.

3. Gowers W. Epilepsy and other chronic convulsive diseases: their

causes. Symptoms Treat. 1901(1):75-6.

4. Mount L RS. Familial paroxysmal choreoathetosis. Arch Neurol Sci. 1940(44):841-7.

5. Kertesz A. Paroxysmal kinesigenic choreoathetosis. An entity within the paroxysmal choreoathetosis syndrome. Description of 10 cases, including 1 autopsied. Neurology. 1967;17(7):680-90. doi: 10.1212/wnl.17.7.680. PubMed PMID: 6067487.

6. Lance JW. Familial paroxysmal dystonic choreoathetosis and its differentiation from related syndromes. Ann Neurol. 1977;2(4):285-93. doi: 10.1002/ana.410020405. PubMed PMID: 617268. 7. Demirkiran M, Jankovic J. Paroxysmal dyskinesias: clinical features and classification. Ann Neurol. 1995;38(4):571-9. doi: 10.1002/ana.410380405. PubMed PMID: 7574453.

8. Bruno MK, Lee HY, Auburger GW, Friedman A, Nielsen JE, Lang AE, et al. Genotypephenotype correlation of paroxysmal nonkinesigenic dyskinesia. Neurology. 2007;68(21):1782-9. doi: 10.1212/01.wnl.0000262029.91552.e0. PubMed PMID: 17515540.

9. Erro R, Sheerin UM, Bhatia KP. Paroxysmal dyskinesias revisited: a review of 500 genetically proven cases and a new classification. Mov Disord. 2014;29(9):1108-16. doi: 10.1002/mds.25933. PubMed PMID: 24963779.

10. Bhatia KP. Familial (idiopathic) paroxysmal dyskinesias: an update. Seminars in neurology. 2001;21(1):69-74. PubMed PMID: 11346027.

11. Bruno MK, Hallett M, Gwinn-Hardy K, Sorensen B, Considine E, Tucker S, et al. Clinical evaluation of idiopathic paroxysmal kinesigenic dyskinesia: new diagnostic criteria. Neurology. 2004;63(12):2280-7. doi: 10.1212/01.wnl.0000147298.05983.50. PubMed PMID: 15623687. 12. Houser MK, Soland VL, Bhatia KP, Quinn NP, Marsden CD. Paroxysmal kinesigenic choreoathetosis: a report of 26 patients. Journal of neurology. 1999;246(2):120-6. PubMed PMID: 10195407.

13. Bhatia KP. Paroxysmal dyskinesias. Movement disorders : official journal of the Movement Disorder Society. 2011;26(6):1157-65. doi: 10.1002/mds.23765. PubMed PMID: 21626559.

14. Chen WJ, Lin Y, Xiong ZQ, Wei W, Ni W, Tan GH, et al. Exome sequencing identifies truncating mutations in PRRT2 that cause paroxysmal kinesigenic dyskinesia. Nat Genet. 2011;43(12):1252-5. doi: 10.1038/ng.1008. PubMed PMID: 22101681.

15. Wang JL, Cao L, Li XH, Hu ZM, Li JD, Zhang JG, et al. Identification of PRRT2 as the causative gene of paroxysmal kinesigenic dyskinesias. Brain : a journal of neurology. 2011;134(Pt 12):3493501. doi: 10.1093/brain/awr289. PubMed PMID: 22120146; PubMed Central PMCID: PMCPMC3235563.

16. Li J, Zhu X, Wang X, Sun W, Feng B, Du T, et al. Targeted genomic sequencing identifies PRRT2 mutations as a cause of paroxysmal kinesigenic choreoathetosis. J Med Genet. 2012;49(2):76- 
8. doi: 10.1136/jmedgenet-2011-100635. PubMed PMID: 22131361; PubMed Central PMCID: PMCPMC3261727.

17. Braak H, Brettschneider J, Ludolph AC, Lee VM, Trojanowski JQ, Del Tredici K. Amyotrophic lateral sclerosis--a model of corticofugal axonal spread. Nature reviews Neurology. 2013;9(12):70814. doi: 10.1038/nrneurol.2013.221. PubMed PMID: 24217521; PubMed Central PMCID: PMC3943211.

18. Lee HY, Huang $\mathrm{Y}$, Bruneau N, Roll P, Roberson ED, Hermann M, et al. Mutations in the gene PRRT2 cause paroxysmal kinesigenic dyskinesia with infantile convulsions. Cell Rep. 2012;1(1):2-12. doi: 10.1016/j.celrep.2011.11.001. PubMed PMID: 22832103; PubMed Central PMCID: PMCPMC3334308.

19. Ebrahimi-Fakhari D, Saffari A, Westenberger A, Klein C. The evolving spectrum of PRRT2associated paroxysmal diseases. Brain : a journal of neurology. 2015;138(Pt 12):3476-95. doi: 10.1093/brain/awv317. PubMed PMID: 26598493.

20. McGovern EM, Roze E, Counihan TJ. The expanding spectrum of paroxysmal movement disorders: update from clinical features to therapeutics. Current opinion in neurology. 2018;31(4):491-7. doi: 10.1097/WCO.0000000000000576. PubMed PMID: 29771692.

21. Heron SE, Grinton BE, Kivity S, Afawi Z, Zuberi SM, Hughes JN, et al. PRRT2 mutations cause benign familial infantile epilepsy and infantile convulsions with choreoathetosis syndrome. American journal of human genetics. 2012;90(1):152-60. doi: 10.1016/j.ajhg.2011.12.003. PubMed PMID: 22243967; PubMed Central PMCID: PMCPMC3257886.

22. Gardiner AR, Jaffer F, Dale RC, Labrum R, Erro R, Meyer E, et al. The clinical and genetic heterogeneity of paroxysmal dyskinesias. Brain : a journal of neurology. 2015;138(Pt 12):3567-80. doi: 10.1093/brain/awv310. PubMed PMID: 26598494; PubMed Central PMCID: PMCPMC4655345. 23. Gardella E, Becker F, Moller RS, Schubert J, Lemke JR, Larsen LH, et al. Benign infantile seizures and paroxysmal dyskinesia caused by an SCN8A mutation. Annals of neurology. 2016;79(3):428-36. doi: 10.1002/ana.24580. PubMed PMID: 26677014.

24. Larsen J, Carvill GL, Gardella E, Kluger G, Schmiedel G, Barisic N, et al. The phenotypic spectrum of SCN8A encephalopathy. Neurology. 2015;84(5):480-9. doi:

10.1212/WNL.0000000000001211. PubMed PMID: 25568300; PubMed Central PMCID: PMCPMC4336074.

25. Tian WT, Huang XJ, Mao X, Liu Q, Liu XL, Zeng S, et al. Proline-rich transmembrane protein 2negative paroxysmal kinesigenic dyskinesia: Clinical and genetic analyses of 163 patients. Movement disorders : official journal of the Movement Disorder Society. 2018;33(3):459-67. doi:

10.1002/mds.27274. PubMed PMID: 29356177.

26. Yin XM, Lin JH, Cao L, Zhang TM, Zeng S, Zhang KL, et al. Familial paroxysmal kinesigenic dyskinesia is associated with mutations in the KCNA1 gene. Human molecular genetics. 2018;27(4):757-8. doi: 10.1093/hmg/ddy025. PubMed PMID: 29351621.

27. Weber A, Kohler A, Hahn A, Neubauer B, Muller U. Benign infantile convulsions (IC) and subsequent paroxysmal kinesigenic dyskinesia (PKD) in a patient with $16 \mathrm{p} 11.2$ microdeletion syndrome. Neurogenetics. 2013;14(3-4):251-3. doi: 10.1007/s10048-013-0376-7. PubMed PMID: 24100940.

28. Rainier S, Thomas D, Tokarz D, Ming L, Bui M, Plein E, et al. Myofibrillogenesis regulator 1 gene mutations cause paroxysmal dystonic choreoathetosis. Arch Neurol. 2004;61(7):1025-9. doi: 10.1001/archneur.61.7.1025. PubMed PMID: 15262732.

29. Du W, Bautista JF, Yang H, Diez-Sampedro A, You SA, Wang L, et al. Calcium-sensitive potassium channelopathy in human epilepsy and paroxysmal movement disorder. Nat Genet. 2005;37(7):733-8. doi: 10.1038/ng1585. PubMed PMID: 15937479.

30. Anheim M, Maillart E, Vuillaumier-Barrot S, Flamand-Rouviere C, Pineau F, Ewenczyk C, et al. Excellent response to acetazolamide in a case of paroxysmal dyskinesias due to GLUT1-deficiency. Journal of neurology. 2011;258(2):316-7. doi: 10.1007/s00415-010-5702-5. PubMed PMID: 20830593. 
31. Weber YG, Kamm C, Suls A, Kempfle J, Kotschet K, Schule R, et al. Paroxysmal choreoathetosis/spasticity (DYT9) is caused by a GLUT1 defect. Neurology. 2011;77(10):959-64. doi: 10.1212/WNL.0b013e31822e0479. PubMed PMID: 21832227.

32. Roubergue A, Roze E, Vuillaumier-Barrot S, Fontenille MJ, Meneret A, Vidailhet $M$, et al. The multiple faces of the ATP1A3-related dystonic movement disorder. Movement disorders : official journal of the Movement Disorder Society. 2013;28(10):1457-9. doi: 10.1002/mds.25396. PubMed PMID: 23483595.

33. Pittock SJ, Joyce C, O'Keane V, Hugle B, Hardiman MO, Brett F, et al. Rapid-onset dystoniaparkinsonism: a clinical and genetic analysis of a new kindred. Neurology. 2000;55(7):991-5. doi: 10.1212/wnl.55.7.991. PubMed PMID: 11061257.

34. Rosewich $\mathrm{H}$, Thiele $\mathrm{H}$, Ohlenbusch $\mathrm{A}$, Maschke $\mathrm{U}$, Altmuller J, Frommolt $\mathrm{P}$, et al. Heterozygous de-novo mutations in ATP1A3 in patients with alternating hemiplegia of childhood: a whole-exome sequencing gene-identification study. Lancet Neurol. 2012;11(9):764-73. doi: 10.1016/S1474-4422(12)70182-5. PubMed PMID: 22850527.

35. Friedman JR, Meneret A, Chen DH, Trouillard O, Vidailhet M, Raskind WH, et al. ADCY5 mutation carriers display pleiotropic paroxysmal day and nighttime dyskinesias. Movement disorders : official journal of the Movement Disorder Society. 2016;31(1):147-8. doi: 10.1002/mds.26494. PubMed PMID: 26686870; PubMed Central PMCID: PMCPMC4724296.

36. Carecchio M, Schneider SA, Chan H, Lachmann R, Lee PJ, Murphy E, et al. Movement disorders in adult surviving patients with maple syrup urine disease. Movement disorders : official journal of the Movement Disorder Society. 2011;26(7):1324-8. doi: 10.1002/mds.23629. PubMed PMID: 21484869; PubMed Central PMCID: PMCPMC4235248.

37. Temudo T, Martins E, Pocas F, Cruz R, Vilarinho L. Maple syrup disease presenting as paroxysmal dystonia. Annals of neurology. 2004;56(5):749-50. doi: 10.1002/ana.20288. PubMed PMID: 15505779.

38. Chen DH, Meneret A, Friedman JR, Korvatska O, Gad A, Bonkowski ES, et al. ADCY5-related dyskinesia: Broader spectrum and genotype-phenotype correlations. Neurology. 2015;85(23):202635. doi: 10.1212/WNL.0000000000002058. PubMed PMID: 26537056; PubMed Central PMCID: PMCPMC4676753.

39. Zorzi G, Castellotti B, Zibordi F, Gellera C, Nardocci N. Paroxysmal movement disorders in GLUT1 deficiency syndrome. Neurology. 2008;71(2):146-8. doi: 10.1212/01.wnl.0000316804.10020.ba. PubMed PMID: 18606970.

40. Pons R, Collins A, Rotstein M, Engelstad K, De Vivo DC. The spectrum of movement disorders in Glut-1 deficiency. Movement disorders : official journal of the Movement Disorder Society. 2010;25(3):275-81. doi: 10.1002/mds.22808. PubMed PMID: 20063428.

41. Schneider SA, Paisan-Ruiz C, Garcia-Gorostiaga I, Quinn NP, Weber YG, Lerche H, et al. GLUT1 gene mutations cause sporadic paroxysmal exercise-induced dyskinesias. Movement disorders : official journal of the Movement Disorder Society. 2009;24(11):1684-8. doi: 10.1002/mds.22507. PubMed PMID: 19630075.

42. Wang D, Pascual JM, Yang H, Engelstad K, Jhung S, Sun RP, et al. Glut-1 deficiency syndrome: clinical, genetic, and therapeutic aspects. Annals of neurology. 2005;57(1):111-8. doi: 10.1002/ana.20331. PubMed PMID: 15622525.

43. Suls A, Dedeken P, Goffin K, Van Esch H, Dupont P, Cassiman D, et al. Paroxysmal exerciseinduced dyskinesia and epilepsy is due to mutations in SLC2A1, encoding the glucose transporter GLUT1. Brain : a journal of neurology. 2008;131(Pt 7):1831-44. doi: 10.1093/brain/awn113. PubMed PMID: 18577546; PubMed Central PMCID: PMCPMC2442425.

44. Leen WG, Klepper J, Verbeek MM, Leferink M, Hofste T, van Engelen BG, et al. Glucose transporter-1 deficiency syndrome: the expanding clinical and genetic spectrum of a treatable disorder. Brain : a journal of neurology. 2010;133(Pt 3):655-70. doi: 10.1093/brain/awp336. PubMed PMID: 20129935. 
45. Weber YG, Storch A, Wuttke TV, Brockmann K, Kempfle J, Maljevic S, et al. GLUT1 mutations are a cause of paroxysmal exertion-induced dyskinesias and induce hemolytic anemia by a cation leak. J Clin Invest. 2008;118(6):2157-68. doi: 10.1172/JCI34438. PubMed PMID: 18451999; PubMed Central PMCID: PMCPMC2350432.

46. Friedman J, Feigenbaum A, Chuang N, Silhavy J, Gleeson JG. Pyruvate dehydrogenase complex-E2 deficiency causes paroxysmal exercise-induced dyskinesia. Neurology. 2017;89(22):2297-8. doi: 10.1212/WNL.0000000000004689. PubMed PMID: 29093066; PubMed Central PMCID: PMCPMC5705245.

47. Olgiati S, Skorvanek M, Quadri M, Minneboo M, Graafland J, Breedveld GJ, et al. Paroxysmal exercise-induced dystonia within the phenotypic spectrum of ECHS1 deficiency. Movement disorders : official journal of the Movement Disorder Society. 2016;31(7):1041-8. doi: 10.1002/mds.26610. PubMed PMID: 27090768.

48. Bozi M, Bhatia KP. Paroxysmal exercise-induced dystonia as a presenting feature of youngonset Parkinson's disease. Movement disorders : official journal of the Movement Disorder Society. 2003;18(12):1545-7. doi: 10.1002/mds.10597. PubMed PMID: 14673897.

49. Dale RC, Melchers A, Fung VS, Grattan-Smith P, Houlden H, Earl J. Familial paroxysmal exercise-induced dystonia: atypical presentation of autosomal dominant GTP-cyclohydrolase 1 deficiency. Dev Med Child Neurol. 2010;52(6):583-6. doi: 10.1111/j.1469-8749.2010.03619.x. PubMed PMID: 20187889.

50. Blakeley J, Jankovic J. Secondary paroxysmal dyskinesias. Movement disorders : official journal of the Movement Disorder Society. 2002;17(4):726-34. doi: 10.1002/mds.10178. PubMed PMID: 12210862.

51. Strzelczyk A, Burk K, Oertel WH. Treatment of paroxysmal dyskinesias. Expert Opin Pharmacother. 2011;12(1):63-72. doi: 10.1517/14656566.2010.513971. PubMed PMID: 21108579.

52. Huang $X J$, Wang $T$, Wang JL, Liu XL, Che XQ, Li J, et al. Paroxysmal kinesigenic dyskinesia: Clinical and genetic analyses of 110 patients. Neurology. 2015;85(18):1546-53. doi:

10.1212/WNL.0000000000002079. PubMed PMID: 26446061.

53. Gardiner AR, Bhatia KP, Stamelou M, Dale RC, Kurian MA, Schneider SA, et al. PRRT2 gene mutations: from paroxysmal dyskinesia to episodic ataxia and hemiplegic migraine. Neurology. 2012;79(21):2115-21. doi: 10.1212/WNL.0b013e3182752c5a. PubMed PMID: 23077024; PubMed Central PMCID: PMCPMC3511930.

54. Labate A, Tarantino P, Viri M, Mumoli L, Gagliardi M, Romeo A, et al. Homozygous c.649dupC mutation in PRRT2 worsens the BFIS/PKD phenotype with mental retardation, episodic ataxia, and absences. Epilepsia. 2012;53(12):e196-9. doi: 10.1111/epi.12009. PubMed PMID: 23126439.

55. Delcourt M, Riant F, Mancini J, Milh M, Navarro V, Roze E, et al. Severe phenotypic spectrum of biallelic mutations in PRRT2 gene. Journal of neurology, neurosurgery, and psychiatry. 2015;86(7):782-5. doi: 10.1136/jnnp-2014-309025. PubMed PMID: 25595153.

56. Yang Y, Su Y, Guo Y, Ding Y, Xu S, Jiang Y, et al. Oxcarbazepine versus carbamazepine in the treatment of paroxysmal kinesigenic dyskinesia. Int J Neurosci. 2012;122(12):719-22. doi: 10.3109/00207454.2012.715109. PubMed PMID: 22856516.

57. Goodenough DJ, Fariello RG, Annis BL, Chun RW. Familial and acquired paroxysmal dyskinesias. A proposed classification with delineation of clinical features. Arch Neurol. 1978;35(12):827-31. doi: 10.1001/archneur.1978.00500360051010. PubMed PMID: 718486.

58. Chatterjee A, Louis ED, Frucht S. Levetiracetam in the treatment of paroxysmal kinesiogenic choreoathetosis. Movement disorders : official journal of the Movement Disorder Society. 2002;17(3):614-5. doi: 10.1002/mds.10118. PubMed PMID: 12112221.

59. Chudnow RS, Mimbela RA, Owen DB, Roach ES. Gabapentin for familial paroxysmal dystonic choreoathetosis. Neurology. 1997;49(5):1441-2. doi: 10.1212/wnl.49.5.1441. PubMed PMID: 9371936. 
60. Uberall MA, Wenzel D. Effectiveness of lamotrigine in children with paroxysmal kinesigenic choreoathetosis. Dev Med Child Neurol. 2000;42(10):699-700. PubMed PMID: 11085299.

61. Huang YG, Chen YC, Du F, Li R, Xu GL, Jiang W, et al. Topiramate therapy for paroxysmal kinesigenic choreoathetosis. Movement disorders : official journal of the Movement Disorder Society. 2005;20(1):75-7. doi: 10.1002/mds.20283. PubMed PMID: 15390133.

62. Li M, Niu F, Zhu X, Wu X, Shen N, Peng X, et al. PRRT2 Mutant Leads to Dysfunction of Glutamate Signaling. Int J Mol Sci. 2015;16(5):9134-51. doi: 10.3390/ijms16059134. PubMed PMID: 25915028; PubMed Central PMCID: PMCPMC4463582.

63. Kumar A, Szekely A, Jabbari B. Effective Treatment of Paroxysmal Nonkinesigenic Dyskinesia With Oxcarbazepine. Clin Neuropharmacol. 2016;39(4):201-5. doi:

10.1097/WNF.0000000000000149. PubMed PMID: 27046658.

64. Mink JW. Treatment of paroxysmal dyskinesias in children. Curr Treat Options Neurol. 2015;17(6):350. doi: 10.1007/s11940-015-0350-9. PubMed PMID: 25864940.

65. Alemdar M, Iseri P, Selekler M, Komsuoglu SS. Levetiracetam-responding paroxysmal nonkinesigenic dyskinesia. Clin Neuropharmacol. 2007;30(4):241-4. doi:

10.1097/wnf.0b013e31803b9415. PubMed PMID: 17762321.

66. Coulter DL, Donofrio P. Haloperidol for nonkinesiogenic paroxysmal dyskinesia. Arch Neurol. 1980;37(5):325-6. doi: 10.1001/archneur.1980.00500540103027. PubMed PMID: 7387459.

67. Loscher W, Richter A. Piracetam and levetiracetam, two pyrrolidone derivatives, exert antidystonic activity in a hamster model of paroxysmal dystonia. Eur J Pharmacol. 2000;391(3):2514. doi: 10.1016/s0014-2999(00)00105-9. PubMed PMID: 10729365.

68. Chang FC, Westenberger A, Dale RC, Smith M, Pall HS, Perez-Duenas B, et al. Phenotypic insights into ADCY5-associated disease. Movement disorders : official journal of the Movement Disorder Society. 2016;31(7):1033-40. doi: 10.1002/mds.26598. PubMed PMID: 27061943; PubMed Central PMCID: PMCPMC4950003.

69. Masoud M, Gordon K, Hall A, Jasien J, Lardinois K, Uchitel J, et al. Motor function domains in alternating hemiplegia of childhood. Dev Med Child Neurol. 2017;59(8):822-8. doi:

10.1111/dmcn.13443. PubMed PMID: 28543714.

70. Mahajan A, Constantinou J, Sidiropoulos C. ECHS1 deficiency-associated paroxysmal exercise-induced dyskinesias: case presentation and initial benefit of intervention. Journal of neurology. 2017;264(1):185-7. doi: 10.1007/s00415-016-8381-z. PubMed PMID: 28039521.

71. Erro R, Bhatia KP. Unravelling of the paroxysmal dyskinesias. Journal of neurology, neurosurgery, and psychiatry. 2019;90(2):227-34. doi: 10.1136/jnnp-2018-318932. PubMed PMID: 30242089.

72. Ramm-Pettersen A, Nakken KO, Skogseid IM, Randby H, Skei EB, Bindoff LA, et al. Good outcome in patients with early dietary treatment of GLUT-1 deficiency syndrome: results from a retrospective Norwegian study. Dev Med Child Neurol. 2013;55(5):440-7. doi: 10.1111/dmcn.12096. PubMed PMID: 23448551.

73. Leen WG, Mewasingh L, Verbeek MM, Kamsteeg EJ, van de Warrenburg BP, Willemsen MA. Movement disorders in GLUT1 deficiency syndrome respond to the modified Atkins diet. Movement disorders : official journal of the Movement Disorder Society. 2013;28(10):1439-42. doi:

10.1002/mds.25515. PubMed PMID: 23801573.

74. Mochel F, Hainque E, Gras D, Adanyeguh IM, Caillet S, Heron B, et al. Triheptanoin dramatically reduces paroxysmal motor disorder in patients with GLUT1 deficiency. Journal of neurology, neurosurgery, and psychiatry. 2016;87(5):550-3. doi: 10.1136/jnnp-2015-311475. PubMed PMID: 26536893; PubMed Central PMCID: PMCPMC4853553.

75. McWilliam CA, Ridout CK, Brown RM, McWilliam RC, Tolmie J, Brown GK. Pyruvate dehydrogenase E2 deficiency: a potentially treatable cause of episodic dystonia. Eur J Paediatr Neurol. 2010;14(4):349-53. doi: 10.1016/j.ejpn.2009.11.001. PubMed PMID: 20022530. 
76. Horisawa S, Sumi M, Akagawa H, Kawamata T, Taira T. Thalamotomy for paroxysmal kinesigenic dyskinesias in a multiplex family. European journal of neurology. 2017;24(10):e71-e2. doi: 10.1111/ene.13379. PubMed PMID: 28906077.

77. Kaufman CB, Mink JW, Schwalb JM. Bilateral deep brain stimulation for treatment of medically refractory paroxysmal nonkinesigenic dyskinesia. Journal of neurosurgery.

2010;112(4):847-50. doi: 10.3171/2009.9.JNS09454. PubMed PMID: 19799495.

78. van Coller R, Slabbert P, Vaidyanathan J, Schutte C. Successful treatment of disabling paroxysmal nonkinesigenic dyskinesia with deep brain stimulation of the globus pallidus internus. Stereotact Funct Neurosurg. 2014;92(6):388-92. doi: 10.1159/000365226. PubMed PMID: 25359315. 79. Meijer IA, Miravite J, Kopell BH, Lubarr N. Deep Brain Stimulation in an Additional Patient With ADCY5-Related Movement Disorder. J Child Neurol. 2017;32(4):438-9. doi: 10.1177/0883073816681353. PubMed PMID: 27920267.

80. Bhatia KP, Marsden CD, Thomas DG. Posteroventral pallidotomy can ameliorate attacks of paroxysmal dystonia induced by exercise. Journal of neurology, neurosurgery, and psychiatry. 1998;65(4):604-5. doi: 10.1136/jnnp.65.4.604a. PubMed PMID: 9771800; PubMed Central PMCID: PMCPMC2170286. 